Review Article

\title{
Nigral Iron Elevation Is an Invariable Feature of Parkinson's Disease and Is a Sufficient Cause of Neurodegeneration
}

\author{
Scott Ayton and Peng Lei \\ The Florey Institute of Neuroscience and Mental Health, University of Melbourne, Kenneth Myer Building at \\ Genetics Lane on Royal Parade, Parkville, VIC 3010, Australia \\ Correspondence should be addressed to Scott Ayton; scott.ayton@unimelb.edu.au and Peng Lei; peng.lei@florey.edu.au
}

Received 30 April 2013; Accepted 28 October 2013; Published 16 January 2014

Academic Editor: Maha Zaki Rizk

Copyright (C) 2014 S. Ayton and P. Lei. This is an open access article distributed under the Creative Commons Attribution License, which permits unrestricted use, distribution, and reproduction in any medium, provided the original work is properly cited.

Parkinson's disease (PD) is a neurodegenerative disorder characterized by motor deficits accompanying degeneration of substantia nigra pars compactor (SNc) neurons. Although familial forms of the disease exist, the cause of sporadic PD is unknown. Symptomatic treatments are available for PD, but there are no disease modifying therapies. While the neurodegenerative processes in PD may be multifactorial, this paper will review the evidence that prooxidant iron elevation in the SNc is an invariable feature of sporadic and familial PD forms, participates in the disease mechanism, and presents as a tractable target for a disease modifying therapy.

\section{Introduction}

The substantia nigra pars compactor (SNc) degenerates in Parkinson's disease (PD), which precipitates motor disabilities such as tremor and bradykinesia that characterize the disease. Symptomatic therapy, such as Levodopa, restores dopamine levels but is ineffectual in altering the progression of the disease. While multiple brain regions are decorated by Lewy bodies (the defining pathological feature of PD) [1], it is unknown why the SNc is selectively vulnerable to neurodegeneration. Prooxidant iron accumulation in this nucleus is one possible reason. The $\mathrm{SNc}$ is particularly rich in iron [2], which increases with age [3]. PD is complicated by exaggerated iron retention in this nucleus, which was a historically early finding [4], and has since been repeatedly observed using various quantifiable techniques (Table 1). It is proposed that this high basal iron content, with the vulnerability to accumulate iron with age and in disease, makes this region susceptible to PD neurodegeneration. However, a limitation of postmortem tissue analysis is that, most likely, the tissues analyzed were obtained from endstage patients, and from this evidence alone it is not possible to claim if iron is pathogenic in the disease or if it is an epiphenomenon.

\section{Iron Accumulation in Parkinson's Disease: Cause or Effect?}

Is iron elevation contributing to neuronal death in Parkinson's disease, or is it simply a feature of dying neurons? To address this important question, this paper will review three separate lines of evidence: (1) in vivo iron-imaging technology, (2) rare genetic disorders of iron metabolism, and (3) animal models.

2.1. In Vivo Iron-Imaging Technology. The iron hypothesis of Parkinson's disease has been revitalized by the ability to visualize and quantify iron elevation in the $\mathrm{SNc}$ of living patients, first by a technique called transcranial sonography (TCS) then later by $\mathrm{T}_{2}{ }^{*}$-weighted MRI. TCS has been employed for a number of years to quantify the echogenicity of the SN in PD patients. Echogenicity refers to the ability of a substance to return the sound wave back to the receiver. Tissue laden with iron has greater echogenicity allowing iron elevation in PD to be visualized with this technique [511]. TCS is a promising diagnostic tool for PD with positive predictive value of $85.7 \%$ and a negative predictive value of $82.9 \%$ [10]. TCS has been suggested as the earliest predictive test for PD (with the exception of genetic testing in rare 
TABLE 1: Reports of quantifiable iron in PD SN.

\begin{tabular}{lcc}
\hline Iron measurement technique & $\begin{array}{c}\text { Fe in PD SN } \\
(\% \text { control) }\end{array}$ & Reference \\
\hline ICP-MS & 135 & {$[116]$} \\
SP & 176 & {$[117]$} \\
SP & 177 & {$[118]$} \\
AAS & 107 & {$[119]$} \\
ICP-MS & 133 & {$[120]$} \\
ICP-MS & 130 & {$[121]$} \\
X-Ray Microprobe analysis & 340 & {$[122]$} \\
SP & 150 & {$[123]$} \\
Laser microprobe analysis & 145 & {$[124]$} \\
ICPMS & 156 & {$[125]$} \\
Colorimetry & 82 & {$[126]$} \\
X-Ray absorption fine structure & 201 & {$[127]$} \\
Electron probe X-Ray & & \\
microanalysis & 200 & {$[128]$} \\
coupled with cathodoluminescence & & \\
spectroscopy & & {$[96]$} \\
AAS & 144 & {$[129]$} \\
X-Ray fluorescence & 155 & {$[110]$} \\
ICP-MS & 140 & {$[26]$} \\
AAS & 139 & \\
\hline Average & 159.5 & \\
\hline
\end{tabular}

ICPMS: inductively coupled plasma mass spectrometry; SP: spectrophotometry; AAS: atomic absorption spectrometry.

familial cases) [12]. Increased echogenicity in otherwise healthy individuals has been associated with reduced [18F]dopa uptake in the striatum [13] and minor motor abnormalities in older patients [14] possibly suggesting early, presymptomatic degeneration. Tellingly, nonsymptomatic individuals with increased echogenicity have 17 times the risk of acquiring PD after 3 years when compared to individuals with a normal echogenetic profile [15]. The early elevation of iron identified using in vivo imaging techniques could position this phenomenon upstream of neurodegeneration in the PD mechanism.

Increased iron in the SN has also been determined by quantifying relaxation times of $\mathrm{T}_{2}$ - and $\mathrm{T}_{2}{ }^{*}$-weighted MRI, which strongly correlates with tissue iron levels [16]. Iron elevation by MRI has been correlated with disease severity $[17,18]$ and duration [19]. In a 3-year-followup study, iron measured by $\mathrm{T}_{2}{ }^{*}$ MRI was shown to progressively increase in PD subjects but not controls [20]. It also has been implicated in diagnosis of PD with reported sensitivity of $100 \%$ and specificity of $80 \%$ in a small cohort [21].

Iron elevation is also a common feature of familial PD. $\mathrm{PD}$-associated Park genes encoding proteins, alpha synuclein, leucine-rich repeat kinase 2 (LRRK2), PTEN-induced putative kinase 1 (PINK1), Parkin, and DJ-1, are associated with iron accumulation in the SN as measured by TCS, demonstrating that iron elevation is an invariable feature of multiple PD modalities (Table 2).

Imaging technology has allowed visualization of iron elevation as (a) a risk factor for PD, (b) an early event in the progression of the disease, (c) a feature that correlates with disease severity and duration, and (d) a feature of all causes of PD (measured so far). But imaging technology has not afforded us direct evidence to conclude if iron elevation is epiphenomenal or part of the disease process.

2.2. Rare Genetic Disorders of Brain Iron Metabolism Often Present as $P D$. Evidence placing iron as a mediating factor of $\mathrm{PD}$ neurodegeneration is drawn from rare genetic disorders that are known to interfere with the iron-handling pathway. The following examples demonstrate that a primary elevation in nigral iron is a sufficient cause of Parkinsonian neurodegeneration; thus iron elevation evidenced in familial and sporadic cases of PD has the clear potential to contribute to the degenerative process.

2.2.1. Aceruloplasminemia. Ceruloplasmin is multicopper oxidase that converts ferrous to ferric iron and is required for the export of iron from cells [22]. Aceruloplasminemia is a rare genetic disorder of ceruloplasmin dysfunction that results in an iron retention within various tissues $[23,24]$ that can be recapitulated in ceruloplasmin knockout mice [2527]. Dozens of ceruloplasmin mutations have been identified and some induce Parkinsonism in affected individuals [28]. In particular, three missense mutations in ceruloplasminI63T, D554E, and R793H, have been shown to exhibit reduced ferroxidase activity in the plasma of patients [29], increased nigral iron content, and a Parkinsonian presentation in affected individuals [30].

2.2.2. Neurodegeneration with Brain Iron Accumulation Type 1. Neurodegeneration with brain iron accumulation type 1 (NBIA1) is caused by a mutation in pantothenate kinase 2 (PANK2). PANK2 catalyses the initial step in coenzyme A synthesis and mutations have reduced catalytic activity [31] and basal ganglia iron accumulation [32]. Patients with this mutation often present with Parkinsonism [33]. Brains of affected patients contain the Parkinson's Lewy body pathology [34-36], possibly suggesting that iron accumulation is upstream of alpha synuclein deposition in idiopathic PD.

2.2.3. Neuroferritinopathy. Neuroferritinopathy, also called neurodegeneration with brain iron accumulation type 2 , is a rare autosomal dominant neurodegenerative disease caused by one of seven known mutations to the ferritin light chain protein [37-43]. The mutation causes increased iron and ferritin deposition in the brain but not other organs. Iron elevation in the brain results in various extrapyramidal motor symptoms including dystonia, chorea, parkinsonism, and tremor.

2.3. Animal Models. A variety of animal models have demonstrated that iron elevation is sufficient to cause neurodegeneration in the nigra. Direct injection of iron into the midbrain region of rats causes SN neuronal loss [44]. A number of studies employing an iron feeding protocol to neonatal mice have shown Parkinsonism and nigral degeneration in these mice when they reach adulthood [45-47]. These studies take 
TABLE 2: Iron elevation (TCS) in the genetics of PD.

\begin{tabular}{|c|c|c|c|c|c|}
\hline Locus & Gene & Mutation & Comments & $\begin{array}{c}\text { Iron } \\
\text { elevation }\end{array}$ & Reference \\
\hline PARK1/4 & Alpha synuclein & $\begin{array}{l}3 \text { point mutations, } \\
\text { duplication, } \\
\text { triplication }\end{array}$ & $\begin{array}{l}\text { Onset age } 40-50 \\
\text { Rapid progression, frequent dementia. Lewy bodies } \\
\text { present }\end{array}$ & Yes & {$[130]$} \\
\hline PARK2 & Parkin & $>100$ mutations & $\begin{array}{l}\text { Age of onset } 17-24 \text { years } \\
\text { Parkinsonism } \\
\text { Other motor symptoms but no dementia. Lewy bodies } \\
\text { present }\end{array}$ & Yes & {$[130,131]$} \\
\hline PARK6 & PINK1 & $>20$ mutations & $\begin{array}{l}\text { Onset age } 30-50 \\
\text { Clinical features resemble Parkin mutations. Lewy bodies } \\
\text { present }\end{array}$ & Yes & {$[130,132]$} \\
\hline PARK7 & DJ-1 & 3 point mutations & $\begin{array}{l}\text { Onset age } 20-40 \\
\text { Clinical features resemble Parkin mutations. Unknown if } \\
\text { Lewy bodies are present }\end{array}$ & Yes & [130] \\
\hline PARK8 & LRRK2 & 6 point mutations & $\begin{array}{l}\text { Age of onset 50s } \\
\text { Resembles idiopathic PD. Lewy bodies present }\end{array}$ & Yes & {$[130,133]$} \\
\hline PARK9 & ATP13A2 & 1 mutation & $\begin{array}{l}\text { Age of onset } 10-30 \text { years } \\
\text { Parkinsonism, } \\
\text { supranuclear gaze paresis, pyramidal signs, and dementia. } \\
\text { Unknown if Lewy bodies are present }\end{array}$ & $? ?$ & \\
\hline PARK14 & PLA2G6 & 2 mutations & $\begin{array}{l}\text { Age of onset } 20-40 \\
\text { Parkinsonism } \\
\text { Dementia, psychosis, dystonia, and hyperreflexia. } \\
\text { Unknown if Lewy bodies are present }\end{array}$ & $? ?$ & \\
\hline PARK15 & FBXO7 & 3 mutations & $\begin{array}{l}\text { Age of onset } 7-22 \\
\text { Parkinsonism, } \\
\text { hyperreflexia, and spasticity. Unknown if Lewy bodies are } \\
\text { present }\end{array}$ & $? ?$ & \\
\hline
\end{tabular}

Iron accumulation [130-133] and Lewy bodies [134].

advantage of the immature blood brain barrier which allows elevated systemic iron to permeate the brain. Neonatal iron fed mice are also more susceptible to 1-methyl-4-phenyl1,2,3,6-tetrahydropyridine (MPTP) intoxication [48].

Toxin models of PD, MPTP, and 6-hydroxydopamine (6OHDA) also recapitulate iron elevation within the SN [49, $50]$. The changes in iron within the $\mathrm{SN}$ cells are complex and poorly understood. Within the first 2-4 days after treatment of MPTP, there is an increase in chelatable iron within the mitochondria [51], preceding total iron elevation, 1-2 weeks after administration. Iron chelator drugs are effective in attenuating the damage caused by these Parkinsonian toxins $[52,53]$ demonstrating that iron is a mediator of neurodegeneration in toxin models of PD and that iron chelation is an attractive therapeutic option for PD.

\section{The Consequences of Iron Elevation: Implications for the Disease Mechanism}

3.1. Oxidative Stress. Iron elevation can cause oxidative stress-mediated cell death. Within biological systems iron can react with oxygen to catalyze the formation of the toxic hydroxyl radical via the Fenton reaction. This reaction is dependent on the ability of iron to alter its valence state between ferrous $\left(\mathrm{Fe}^{2+}\right)$ and ferric $\left(\mathrm{Fe}^{3+}\right)$ species [54].
Inappropriate iron retention in $\mathrm{PD}$ could promote oxidative stress within this tissue. Post mortem PD-affected brains display increased lipid peroxidation [55], oxidative damage to DNA [56], and lowered levels of the reduced form of glutathione [57], which all reflect oxidative stress.

3.2. Alpha Synuclein Deposition. Alpha synuclein is often considered the Parkinson's protein owning to extensive links to the disease. Three genetic mutations of alpha synuclein, A53T [58], A30P [59], and E46K [60], along with gene duplication [61] or triplication [62] have been associated with inheritable forms of PD. Aggregated alpha synuclein is also the major component of Lewy bodies, the pathological hallmark for PD [63]. Alpha synuclein deposition could be contributed to by iron exposure. Alpha synuclein binds to iron [64-66], which accelerates its aggregation into fibrils [67, 68]. Alpha synuclein has also been shown to directly generate hydrogen peroxide when it aggregates and, in the presence of iron, produce toxic hydroxyl radicals [69]. In cultured neurons, iron has been shown to cause aggregation of alpha synuclein [70-73]. Collectively these findings demonstrate that iron can theoretically impact the aggregation of alpha synuclein. Iron is also found enriched in Lewy bodies [74], providing in vivo evidence that iron elevation could induce Lewy body deposition in PD. 


\section{Mechanisms of Iron Accumulation in PD}

Understanding how iron accumulates in PD may provide opportunities to target this process pharmacologically. There is only a weak association between environmental iron exposure and development of PD [75, 76], suggesting that endogenous factors or metabolic dysregulation is the genesis for elevated iron in PD. Peripheral iron status, modified by diet or various genetic disorders (e.g., hemochromatosis), is rarely reflected by concomitant changes to iron in the brain. While peripheral iron has access to the brain [77] and iron consumed in the diet is distributed to the brain in comparable levels to other organs [78], the brain retains mostly stable throughout life [79-81]. The brain is able to control iron levels in a narrow range by recruiting various protein machinery. While many reviews discuss the iron regulatory pathways of the brain $[82,83]$, this paper will discuss the evidence that fatigue to these machinery results in iron accumulation in PD.

Various iron associated proteins have been investigated for their potential to contribute to iron accumulation in PD. The earliest such study surveyed the iron storage protein ferritin in post mortem PD brains, demonstrating a decrease in this protein compared to controls [84]. Increased iron with a concomitant decrease in ferritin within the SN could suggest an increase in the labile iron pool, making iron more available for toxic interactions. Ferritin elevation, therefore, might be neuroprotective in the disease. This was demonstrated in the MPTP model, where ferritin overexpressing mice were protected against the toxin [52].

While changes in ferritin could relate to cellular buffering capacity of iron, this does not easily explain why iron accumulates in PD. Iron elevation in PD could be contributed to by increased cellular iron uptake via transferrin receptor 1 (TfR1). However, the levels of this protein were shown not to be altered in PD (when loss of neurons was accounted for) [85], nor in the 6-OHDA model [86], arguing against a role for this protein in iron accumulation of PD. Within the periphery, the transferrin receptor is inhibited by the hemochromatosis protein as a normal component of the iron homeostatic mechanism. However, loss of function genetic mutations in the hemochromatosis protein causes pathological iron retention in peripheral tissues in hereditary hemochromatosis. The iron overload associated with hemochromatosis in peripheral tissue is also not convincingly linked to PD. The C282Y mutation in hemochromatosis protein was initially shown to increase the risk of PD and Parkinsonism [87] and this was supported by a later study [88]. However further investigations have failed to find an association with C282Y mutation and PD [89-91], although one study found two single nucleotide polymorphisms (K92N and I217T) in a single PD patient and not in controls [89]. It remains unclear what role hemochromatosis protein plays in either genetic or idiopathic PD; further it is not known if individuals with hereditary hemochromatosis have brain iron accumulation. It is likely that the peripheral hemochromatosis hormone plays a minor role in brain iron homeostasis; indeed staining for the hemochromatosis protein in brain reveals only scattered staining for the protein, localized to parts of cortex, cerebellum, and brain endothelium [92].
Another iron importing protein, transferrin receptor 2 (TfR2) was found to be increased in the rotenone model of PD [93]. It is proposed in the paper by Mastroberardino et al. [93] that TfR2 signals for iron to be deposited in the mitochondria leading to iron accumulation and oxidative damage within the SN. The function consequence of this process is unclear and TfR2 has yet to be explored in human PD tissue.

Both TfR1 and TfR2 receive iron from the transferrin protein. The complex then undergoes endocytosis where iron is transported across the endosome by the divalent metal ion transporter (DMT1). An isoform of DMT1 with an iron responsive element (DMT1 + IRE) was shown to be increased in cultured cells exposed to 6-OHDA [94] and early after MPTP intoxication in mice [95], which was later replicated [96]. Salazar et al. [96] additionally used mice with a loss of function mutation of DMT1 and showed that this was protective against MPTP induced iron elevation and toxicity. Importantly, Salazar et al. [96] also showed that DMT1+IRE was elevated in the SN of PD patients, which implicates overexpression of this protein in iron accumulation in PD.

Iron elevation in PD could also be contributed by failure of iron export. Ferroportin is the only known iron exporting channel in mammals [97]. Ferroportin requires cooperation with a ferroxidase that converts intracellular ferrous iron $\left(\mathrm{Fe}^{2+}\right)$ to ferric iron $\left(\mathrm{Fe}^{3+}\right)$ so that extracellular ferric-binding transferrin protein can remove iron from ferroportin [98]. Ceruloplasmin is the best characterized ferroxidase protein and has been investigated as a possible contributor to iron elevation in PD. Decreased ceruloplasmin ferroxidase activity has been observed in PD cerebrospinal fluid (CSF) [99-101] and serum [102-107], while low serum ceruloplasmin activity is correlated with earlier age of PD onset $[103,105,106]$. Loss of peripheral ceruloplasmin function could therefore impact brain iron levels, and indeed peripheral and brainderived pools of ceruloplasmin are in exchange [26]. The level of ceruloplasmin in the PD SN is unaltered in the disease [108], but its activity is selectively reduced in the SNc [26]. This is important since loss of ceruloplasmin function, as in aceruloplasminemia, often causes Parkinsonism in affected individuals [28].

Iron export could also be impacted by the tau protein. Tau protein is famously linked with Alzheimer's disease and frontotemporal dementia, but tau protein has been implicated in PD from genetic, pathological, and biochemical perspectives [109]. Tau levels are reduced in the substantia nigra in PD, which obtunds amyloid precursor protein (APP) mediated iron export [110]. APP binds to ferroportin to facilitate iron export [111], and loss of tau prevents APP trafficking to the neuronal surface to perform this function [110]. Tau knockout mice develop iron-mediated Parkinsonism [110], highlighting the neurotoxic potential for a disturbance to this pathway.

\section{Conclusions and Therapeutic Implications}

So is iron elevation the cause of PD? Quite simply the answer has to be no, since there has to be some other process that causes iron to elevate in the first place. The same could be said of any other factor implicated in PD. If alpha synuclein is the cause of Parkinson's disease, what causes the protein 
to aggregate? Understanding the cause of PD may indeed be impossible to define. Even if this was understood, the factor(s) inducing the degenerative process in PD may not be propagating disease progression by the time the patient initially presents with symptoms. The degenerative processes in PD are likely to involve multiple pathways; the goal of our field should be to identify components of the disease mechanism that can be targeted pharmacologically. Iron is one such component. Iron is elevated invariably in the SNc of PD-effected brains, early in the disease processes, and brain iron overload is sufficient to cause Parkinsonism in rare genetic cases or brain iron overload, or in various animal models of PD.

Iron is also a tractable target for pharmacotherapy. Numerous iron chelators are currently in use for peripheral disorders of iron overload [112]. Iron chelator, Deferiprone, was recently shown to benefit PD patients in a phase II clinical trial (PMID: 24251381) [113]. This is the first drug to show a disease-modifying effect for PD, which highlights the potential for targeting iron for PD pharmacotherapy, and strongly implicates iron in the disease mechanism. A limitation of the iron chelators presently in the market is that they were developed to treat peripheral disorders of iron metabolism [114]. Iron chelators that have greater access to the brain through BBB are currently in development $[52,53$, $110,115]$.

There is also opportunity to target cellular mechanisms that cause iron to be elevated in PD. Preventing elevation of DMT1, or restoring the loss of tau or ceruloplasmin, might be additional ways to target the iron lesion. While strategies that prevent the rise in iron or remove excess iron in the disease might not be silver bullets that halt neurodegeneration altogether, the evidence outlined in this review suggests that these approaches might slow the degenerative process and therefore are attractive options for the first disease-modifying therapy for PD.

\section{Conflict of Interests}

The authors declare that there is no conflict of interests regarding the publication of this paper.

\section{Acknowledgments}

This paper is supported by funds from the Australian National Health and Medical Research Council (NHMRC), the Alzheimer's Australia Dementia Research Foundation, and the Operational Infrastructure Support Victorian State Government.

\section{References}

[1] H. Braak, U. Rüb, W. P. Gai, and K. Del Tredici, "Idiopathic Parkinson's disease: possible routes by which vulnerable neuronal types may be subject to neuroinvasion by an unknown pathogen," Journal of Neural Transmission, vol. 110, no. 5, pp. 517-536, 2003.
[2] M. E. Götz, K. Double, M. Gerlach, M. B. H. Youdim, and P. Riederer, "The relevance of iron in the pathogenesis of Parkinson's disease," Annals of the New York Academy of Sciences, vol. 1012, pp. 193-208, 2004.

[3] L. Zecca, M. Gallorini, V. Schünemann et al., "Iron, neuromelanin and ferritin content in the substantia nigra of normal subjects at different ages: consequences for iron storage and neurodegenerative processes," Journal of Neurochemistry, vol. 76, no. 6, pp. 1766-1773, 2001.

[4] J. Lhermitte, W. M. Kraus, and D. McAlpine, "On the occurrence of abnormal deposits of iron in the brain in parkinsonism with special reference to its localisation," Journal of Neurology, Neurosurgery \& Psychiatry, vol. 195, pp. s1-s5, 1924.

[5] D. Berg, C. Grote, W.-D. Rausch et al., "Iron accumulation in the substantia nigra in rats visualized by ultrasound," Ultrasound in Medicine and Biology, vol. 25, no. 6, pp. 901-904, 1999.

[6] D. Berg, W. Roggendorf, U. Schröder et al., "Echogenicity of the substantia nigra: association with increased iron content and marker for susceptibility to nigrostriatal injury," Archives of Neurology, vol. 59, no. 6, pp. 999-1005, 2002.

[7] L. Zecca, D. Berg, T. Arzberger et al., "In vivo detection of iron and neuromelanin by transcranial sonography: a new approach for early detection of substantia nigra damage," Movement Disorders, vol. 20, no. 10, pp. 1278-1285, 2005.

[8] D. Berg, "In vivo detection of iron and neuromelanin by transcranial sonography-a new approach for early detection of substantia nigra damage," Journal of Neural Transmission, vol. 113, no. 6, pp. 775-780, 2006.

[9] D. Berg, H. Hochstrasser, K. J. Schweitzer, and O. Riess, "Disturbance of iron metabolism in Parkinson's diseaseultrasonography as a biomarker," Neurotoxicity Research, vol. 9, no. 1, pp. 1-13, 2006.

[10] J. Prestel, K. J. Schweitzer, A. Hofer, T. Gasser, and D. Berg, "Predictive value of transcranial sonography in the diagnosis of Parkinson's disease," Movement Disorders, vol. 21, no. 10, pp. 1763-1765, 2006.

[11] G. Becker, J. Seufert, U. Bogdahn, H. Reichmann, and K. Reiners, "Degeneration of substantia nigra in chronic Parkinson's disease visualized by transcranial color-coded real-time sonography," Neurology, vol. 45, no. 1, pp. 182-184, 1995.

[12] D. Berg, "Transcranial ultrasound as a risk marker for Parkinson's disease," Movement Disorders, vol. 24, supplement 2, pp. S677-S683, 2009.

[13] S. Behnke, U. Schroeder, U. Dillmann et al., "Hyperechogenicity of the substantia nigra in healthy controls is related to MRI changes and to neuronal loss as determined by F-Dopa PET," NeuroImage, vol. 47, no. 4, pp. 1237-1243, 2009.

[14] D. Berg, C. Siefker, P. Ruprecht-Dörfler, and G. Becker, "Relationship of substantia nigra echogenicity and motor function in elderly subjects," Neurology, vol. 56, no. 1, pp. 13-17, 2001.

[15] D. Berg, K. Seppi, S. Behnke et al., "Enlarged substantia Nigra hyperechogenicity and risk for Parkinson disease: a 37-month 3center study of 1847 older persons," Archives of Neurology, vol. 68, no. 7, pp. 932-937, 2011.

[16] N. Gelman, J. M. Gorell, P. B. Barker et al., "MR imaging of human brain at 3.0 T: preliminary report on transverse relaxation rates and relation to estimated iron content," Radiology, vol. 210, no. 3, pp. 759-767, 1999.

[17] G. Gorell, "Increased iron-related MRI contrast in the substantia nigra in Parkinson's disease," Neurology, vol. 45, no. 7, pp. 1138-1143, 1995. 
[18] H. T. Atasoy, O. Nuyan, T. Tunc, M. Yorubulut, A. E. Unal, and L. E. Inan, “T2-weighted MRI in Parkinson's disease; substantia nigra pars compacta hypointensity correlates with the clinical scores," Neurology India, vol. 52, no. 3, pp. 332-337, 2004.

[19] P. Ryvlin, E. Broussolle, H. Piollet, F. Viallet, Y. Khalfallah, and G. Chazot, "Magnetic resonance imaging evidence of decreased putamenal iron content in idiopathic Parkinson's disease," Archives of Neurology, vol. 52, no. 6, pp. 583-588, 1995.

[20] M. Ulla, J. Marie Bonny, L. Ouchchane et al., "Is $\mathrm{r}^{*}$ a new MRI biomarker for the progression of Parkinson's disease? A longitudinal follow-up," PloS ONE, vol. 8, Article ID e57904, 2013.

[21] R. A. Menke, J. Scholz, K. L. Miller et al., "MRI characteristics of the substantia nigra in Parkinson's disease: a combined quantitative T1 and DTI study," NeuroImage, vol. 47, no. 2, pp. 435-441, 2009.

[22] S. Osaki, D. A. Johnson, and E. Frieden, "The possible significance of the ferrous oxidase activity of ceruloplasmin in normal human serum," The Journal of Biological Chemistry, vol. 241, no. 12, pp. 2746-2751, 1966.

[23] H. Miyajima, Y. Nishimura, and K. Mizoguchi, "Familial apoceruloplasmin deficiency associated with blepharospasm and retinal degeneration," Neurology, vol. 37, no. 5, pp. 761-767, 1987.

[24] K. Yoshida, K. Furihata, S. Takeda et al., "A mutation in the ceruloplasmin gene is associated with systemic hemosiderosis in humans," Nature Genetics, vol. 9, no. 3, pp. 267-272, 1995.

[25] B. N. Patel, R. J. Dunn, S. Y. Jeong, Q. Zhu, J.-P. Julien, and S. David, "Ceruloplasmin regulates iron levels in the CNS and prevents free radical injury," Journal of Neuroscience, vol. 22, no. 15, pp. 6578-6586, 2002.

[26] S. Ayton, P. Lei, J. A. Duce et al., "Ceruloplasmin dysfunction and therapeutic potential for parkinson disease," Annals of Neurology, vol. 73, article 554, 2013.

[27] Z. L. Harris, A. P. Durley, T. K. Man, and J. D. Gitlin, “Targeted gene disruption reveals an essential role for ceruloplasmin in cellular iron efflux," Proceedings of the National Academy of Sciences of the United States of America, vol. 96, no. 19, pp. 1081210817, 1999.

[28] A. McNeill, M. Pandolfo, J. Kuhn, H. Shang, and H. Miyajima, "The neurological presentation of ceruloplasmin gene mutations," European Neurology, vol. 60, no. 4, pp. 200-205, 2008.

[29] H. Hochstrasser, J. Tomiuk, U. Walter et al., "Functional relevance of ceruloplasmin mutations in Parkinson's disease," The FASEB Journal, vol. 19, article 1851, 2005.

[30] H. Hochstrasser, P. Bauer, U. Walter et al., "Ceruloplasmin gene variations and substantia nigra hyperechogenicity in Parkinson disease," Neurology, vol. 63, no. 10, pp. 1912-1917, 2004.

[31] P. T. Kotzbauer, A. C. Truax, J. Q. Trojanowski, and V. M.-Y. Lee, "Altered neuronal mitochondrial coenzyme A synthesis in neurodegeneration with brain iron accumulation caused by abnormal processing, stability, and catalytic activity of mutant pantothenate kinase 2," Journal of Neuroscience, vol. 25, no. 3, pp. 689-698, 2005.

[32] K. F. Swaiman, "Hallervorden-Spatz syndrome and brain iron metabolism," Archives of Neurology, vol. 48, no. 12, pp. 12851293, 1991.

[33] R. Alberca, E. Rafel, I. Chinchon, J. Vadillo, and A. Navarro, "Late onset Parkinsonian syndrome in Hallervorden-Spatz disease," Journal of Neurology Neurosurgery and Psychiatry, vol. 50, no. 12 , pp. $1665-1668,1987$.
[34] S. Arawaka, Y. Saito, S. Murayama, and H. Mori, "Lewy body in neurodegeneration with brain iron accumulation type 1 is immunoreactive for $\alpha$-synuclein," Neurology, vol. 51, no. 3, pp. 887-889, 1998.

[35] G. K. Tofaris, T. Revesz, T. S. Jacques, S. Papacostas, and J. Chataway, "Adult-onset neurodegeneration with brain iron accumulation and cortical $\alpha$-synuclein and tau pathology: a distinct clinicopathological entity," Archives of Neurology, vol. 64, no. 2, pp. 280-282, 2007.

[36] J. E. Galvin, B. Giasson, H. I. Hurtig, V. M.-Y. Lee, and J. Q. Trojanowski, "Neurodegeneration with brain iron accumulation, type 1 is characterized by $\alpha-, \beta$-, and $\gamma$-synuclein neuropathology," The American Journal of Pathology, vol. 157, no. 2, pp. 361-368, 2000.

[37] A. R. J. Curtis, C. Fey, C. M. Morris et al., "Mutation in the gene encoding ferritin light polypeptide causes dominant adultonset basal ganglia disease," Nature Genetics, vol. 28, no. 4, pp. 350-354, 2001.

[38] R. Vidal, B. Ghetti, M. Takao et al., "Intracellular ferritin accumulation in neural and extraneural tissue characterizes a neurodegenerative disease associated with a mutation in the ferritin light polypeptide gene," Journal of Neuropathology and Experimental Neurology, vol. 63, no. 4, pp. 363-380, 2004.

[39] M. Mancuso, G. Davidzon, R. M. Kurlan et al., "Hereditary ferritinopathy: a novel mutation, its cellular pathology, and pathogenetic insights," Journal of Neuropathology and Experimental Neurology, vol. 64, no. 4, pp. 280-294, 2005.

[40] P. Maciel, V. T. Cruz, M. Constante et al., "Neuroferritinopathy: missense mutation in FTL causing early-onset bilateral pallidal involvement," Neurology, vol. 65, no. 4, pp. 603-605, 2005.

[41] E. Ohta, T. Nagasaka, K. Shindo et al., "Neuroferritinopathy in a Japanese family with a duplication in the ferritin light chain gene," Neurology, vol. 70, no. 16, pp. 1493-1494, 2008.

[42] D. Devos, P. J. Tchofo, I. Vuillaume et al., "Clinical features and natural history of neuroferritinopathy caused by the 458dupA FTL mutation," Brain, vol. 132, no. 6, article e109, 2009.

[43] A. Kunota, A. Hida, Y. Ichikawa et al., "A novel ferritin light chain gene mutation in a Japanese family with neuroferritinopathy: description of clinical features and implications for genotype-phenotype correlations," Movement Disorders, vol. 24, no. 3, pp. 441-445, 2009.

[44] D. Ben-Shachar and M. B. H. Youdim, "Intranigral iron injection induces behavioral and biochemical "Parkinsonism" in rats," Journal of Neurochemistry, vol. 57, no. 6, pp. 2133-2135, 1991.

[45] F. Dal-Pizzol, F. Klamt, J. Frota M.L.C. et al., "Neonatal iron exposure induces oxidative stress in adult Wistar rat," Developmental Brain Research, vol. 130, no. 1, pp. 109-114, 2001.

[46] P. Budni, M. N. M. De Lima, M. Polydoro, J. C. F. Moreira, N. Schroder, and F. Dal-Pizzol, "Antioxidant effects of selegiline in oxidative stress induced by iron neonatal treatment in rats," Neurochemical Research, vol. 32, no. 6, pp. 965-972, 2007.

[47] D. Kaur, J. Peng, S. J. Chinta et al., "Increased murine neonatal iron intake results in Parkinson-like neurodegeneration with age," Neurobiology of Aging, vol. 28, no. 6, pp. 907-913, 2007.

[48] J. Lan and D. H. Jiang, "Desferrioxamine and vitamin E protect against iron and MPTP-induced neurodegeneration in mice," Journal of Neural Transmission, vol. 104, no. 4-5, pp. 469-481, 1997.

[49] J. A. Temlett, J. P. Landsberg, F. Watt, and G. W. Grime, "Increased iron in the substantia nigra compacta of the MPTPlesioned hemiparkinsonian African Green monkey: evidence 
from proton microprobe elemental microanalysis," Journal of Neurochemistry, vol. 62, no. 1, pp. 134-146, 1994.

[50] H. Jiang, W.-F. Chen, and J.-X. Xie, "Relationship between dopamine and iron contents in the brain of Parkinsonian rats," Acta Physiologica Sinica, vol. 53, no. 5, pp. 334-338, 2001.

[51] L.-P. Liang and M. Patel, "Iron-sulfur enzyme mediated mitochondrial superoxide toxicity in experimental Parkinson's disease," Journal of Neurochemistry, vol. 90, no. 5, pp. 1076-1084, 2004.

[52] D. Kaur, F. Yantiri, S. Rajagopalan et al., "Genetic or pharmacological iron chelation prevents MPTP-induced neurotoxicity in vivo: a novel therapy for Parkinson's disease," Neuron, vol. 37, no. 6, pp. 899-909, 2003.

[53] D. B. Shachar, N. Kahana, V. Kampel, A. Warshawsky, and M. B. H. Youdim, "Neuroprotection by a novel brain permeable iron chelator, VK-28, against 6-hydroxydopamine lession in rats," Neuropharmacology, vol. 46, no. 2, pp. 254-263, 2004.

[54] K. J. Barnham, C. L. Masters, and A. I. Bush, "Neurodegenerative diseases and oxidatives stress," Nature Reviews Drug Discovery, vol. 3, no. 3, pp. 205-214, 2004.

[55] D. T. Dexter, C. J. Carter, F. R. Wells et al., "Basal lipid peroxidation in substantia nigra is increased in Parkinson's disease," Journal of Neurochemistry, vol. 52, no. 2, pp. 381-389, 1989.

[56] Z. I. Alam, A. Jenner, S. E. Daniel et al., "Oxidative DNA damage in the Parkinsonian brain: an apparent selective increase in 8hydroxyguanine levels in substantia nigra," Journal of Neurochemistry, vol. 69, no. 3, pp. 1196-1203, 1997.

[57] J. Sian, D. T. Dexter, A. J. Lees et al., "Alterations in glutathione levels in Parkinson's disease and other neurodegenerative disorders affecting basal ganglia," Annals of Neurology, vol. 36, no. 3, pp. 348-355, 1994.

[58] M. H. Polymeropoulos, C. Lavedan, E. Leroy et al., "Mutation in the $\alpha$-synuclein gene identified in families with Parkinson's disease," Science, vol. 276, no. 5321, pp. 2045-2047, 1997.

[59] R. Krüger, W. Kuhn, T. Müller et al., "Ala30Pro mutation in the gene encoding $\alpha$-synuclein in Parkinson's disease," Nature Genetics, vol. 18, no. 2, pp. 106-108, 1998.

[60] J. J. Zarranz, J. Alegre, J. C. Gómez-Esteban et al., "The new mutation, E46K, of $\alpha$-synuclein causes parkinson and lewy body dementia," Annals of Neurology, vol. 55, no. 2, pp. 164-173, 2004.

[61] M.-C. Chartier-Harlin, J. Kachergus, C. Roumier et al., " $\alpha$ synuclein locus duplication as a cause of familial Parkinson's disease," The Lancet, vol. 364, no. 9440, pp. 1167-1169, 2004.

[62] D. W. Miller, S. M. Hague, J. Clarimon et al., " $\alpha$-synuclein in blood and brain from familial Parkinson disease with SNCA locus triplication," Neurology, vol. 62, no. 10, pp. 1835-1838, 2004.

[63] M. G. Spillantini, M. L. Schmidt, V. M.-Y. Lee, J. Q. Trojanowski, R. Jakes, and M. Goedert, " $\alpha$-synuclein in Lewy bodies," Nature, vol. 388 , no. 6645 , pp. 839-840, 1997.

[64] B. Bharathi, S. S. Indi, and K. S. J. Rao, "Copper- and ironinduced differential fibril formation in $\alpha$-synuclein: TEM study," Neuroscience Letters, vol. 424, no. 2, pp. 78-82, 2007.

[65] B. Bharathi and K. S. J. Rao, “Thermodynamics imprinting reveals differential binding of metals to $\alpha$-synuclein: relevance to parkinson's disease," Biochemical and Biophysical Research Communications, vol. 359, no. 1, pp. 115-120, 2007.

[66] Y. Peng, C. Wang, H. H. Xu, Y.-N. Liu, and F. Zhou, "Binding of $\alpha$-synuclein with $\mathrm{Fe}(\mathrm{III})$ and with $\mathrm{Fe}(\mathrm{II})$ and biological implications of the resultant complexes," Journal of Inorganic Biochemistry, vol. 104, no. 4, pp. 365-370, 2010.

[67] S. R. Paik, H.-J. Shin, and J.-H. Lee, "Metal-catalyzed oxidation of $\alpha$-synuclein in the presence of copper(II) and hydrogen peroxide," Archives of Biochemistry and Biophysics, vol. 378, no. 2, pp. 269-277, 2000.

[68] N. Golts, H. Snyder, M. Frasier, C. Theisler, P. Choi, and B. Wolozin, "Magnesium inhibits spontaneous and iron-induced aggregation of $\alpha$-synuclein," The Journal of Biological Chemistry, vol. 277, no. 18, pp. 16116-16123, 2002.

[69] S. Turnbull, B. J. Tabner, O. M. A. El-Agnaf, S. Moore, Y. Davies, and D. Allsop, " $\alpha$-synuclein implicated in Parkinson's disease catalyses the formation of hydrogen peroxide in vitro," Free Radical Biology and Medicine, vol. 30, no. 10, pp. 1163-1170, 2001.

[70] Q. He, N. Song, H. Xu, R. Wang, J. Xie, and H. Jiang, "Alphasynuclein aggregation is involved in the toxicity induced by ferric iron to SK-N-SH neuroblastoma cells," Journal of Neural Transmission, vol. 118, no. 3, pp. 397-406, 2011.

[71] W.-J. Li, H. Jiang, N. Song, and J.-X. Xie, "Dose- and timedependent $\alpha$-synuclein aggregation induced by ferric iron in SK-N-SH cells," Neuroscience Bulletin, vol. 26, no. 3, pp. 205210, 2010.

[72] N. Ostrerova-Golts, L. Petrucelli, J. Hardy, J. M. Lee, M. Farer, and B. Wolozin, "The A53T $\alpha$-synuclein mutation increases iron-dependent aggregation and toxicity," Journal of Neuroscience, vol. 20, no. 16, pp. 6048-6054, 2000.

[73] W. Li, H. Jiang, N. Song, and J. Xie, "Oxidative stress partially contributes to iron-induced alpha-synuclein aggregation in SKN-SH cells," Neurotoxicity Research, vol. 19, no. 3, pp. 435-442, 2011.

[74] R. J. Castellani, S. L. Siedlak, G. Perry, and M. A. Smith, "Sequestration of iron by Lewy bodies in Parkinson's disease," Acta Neuropathologica, vol. 100, no. 2, pp. 111-114, 2000.

[75] J. Zayed, S. Ducic, G. Campanella et al., "Environmental factors in the etiology of Parkinson's disease," Canadian Journal of Neurological Sciences, vol. 17, no. 3, pp. 286-291, 1990.

[76] G. Logroscino, K. Marder, J. Graziano et al., "Dietary iron, animal fats, and risk of Parkinson's disease," Movement Disorders, vol. 13, supplement 1, pp. 13-16, 1998.

[77] E. H. Morgan and T. Moos, "Mechanism and developmental changes in iron transport across the blood-brain barrier," Developmental Neuroscience, vol. 24, no. 2-3, pp. 106-113, 2002.

[78] J. H. Chen, S. Shahnavas, N. Singh, W. Y. Ong, and T. Walczyk, "Stable iron isotope tracing reveals significant brain iron uptake in adult rats," Metallomics, vol. 5, article 167, 2013.

[79] P. R. Dallman, M. A. Siimes, and E. C. Manies, "Brain iron: persistent deficiency following short term iron deprivation in the young rat," British Journal of Haematology, vol. 31, no. 2, pp. 209-215, 1975.

[80] P. R. Dallman and R. A. Spirito, "Brain iron in the rat: extremely slow turnover in normal rats may explain long lasting effects of early iron deficiency," Journal of Nutrition, vol. 107, no. 6, pp. 1075-1081, 1977.

[81] D. Ben-Shachar, R. Ashkenazi, and M. B. H. Youdim, "Longterm consequence of early iron-deficiency on dopaminergic neurotransmission in rats," International Journal of Developmental Neuroscience, vol. 4, no. 1, pp. 81-88, 1986.

[82] S. Ayton, P. Lei, and A. I. Bush, "Metallostasis in Alzheimer's disease," Free Radical Biolology and Medicine, vol. 62, pp. 76-89, 2013. 
[83] D. Hare, S. Ayton, A. Bush, and P. Lei, "A delicate balance: iron metabolism and diseases of the brain," Frontiers in Aging Neuroscience, vol. 5, 34, 2013.

[84] D. T. Dexter, A. Carayon, M. Vidailhet et al., "Decreased ferritin levels in brain in Parkinson's disease," Journal of Neurochemistry, vol. 55, no. 1, pp. 16-20, 1990.

[85] B. A. Faucheux, J.-J. Hauw, Y. Agid, and E. C. Hirsch, "The density of [125I]-transferrin binding sites on perikarya of melanized neurons of the substantia nigra is decreased in Parkinson's disease," Brain Research, vol. 749, no. 1, pp. 170-174, 1997.

[86] Y. He, T. Lee, and S. K. Leong, "Time course of dopaminergic cell death and changes in iron, ferritin and transferrin levels in the rat substantia nigra after 6-hydroxydopamine (6-OHDA) lesioning," Free Radical Research, vol. 31, no. 2, pp. 103-112, 1999.

[87] M. C. J. Dekker, P. C. Giesbergen, O. T. Njajou et al., "Mutations in the hemochromatosis gene (HFE), Parkinson's disease and parkinsonism," Neuroscience Letters, vol. 348, no. 2, pp. 117-119, 2003.

[88] R. J. Guerreiro, J. M. Bras, I. Santana et al., "Association of HFE common mutations with Parkinson's disease, Alzheimer's disease and mild cognitive impairment in a Portuguese cohort," BMC Neurology, vol. 6, article 24, 2006.

[89] N. Akbas, H. Hochstrasser, J. Deplazes et al., "Screening for mutations of the HFE gene in Parkinson's disease patients with hyperechogenicity of the substantia nigra," Neuroscience Letters, vol. 407, no. 1, pp. 16-19, 2006.

[90] G. Biasiotto, S. Goldwurm, D. Finazzi et al., "HFE gene mutations in a population of Italian Parkinson's disease patients," Parkinsonism and Related Disorders, vol. 14, no. 5, pp. 426-430, 2008.

[91] A. H. Aamodt, L. J. Stovner, K. Thorstensen, S. Lydersen, L. R. White, and J. O. Aasly, "Prevalence of haemochromatosis gene mutations in Parkinson's disease," Journal of Neurology, Neurosurgery and Psychiatry, vol. 78, no. 3, pp. 315-317, 2007.

[92] J. M. Bastin, M. Jones, C. A. O’Callaghan, L. Schimanski, D. Y. Mason, and A. R. M. Townsend, "Kupffer cell staining by an HFE-specific monoclonal antibody: implications for hereditary haemochromatosis," British Journal of Haematology, vol. 103, no. 4, pp. 931-941, 1998.

[93] P. G. Mastroberardino, E. K. Hoffman, M. P. Horowitz et al., "A novel transferrin/TfR2-mediated mitochondrial iron transport system is disrupted in Parkinson's disease," Neurobiology of Disease, vol. 34, no. 3, pp. 417-431, 2009.

[94] N. Song, H. Jiang, J. Wang, and J.-X. Xie, "Divalent metal transporter 1 up-regulation is involved in the 6-hydroxydopamineinduced ferrous iron influx," Journal of Neuroscience Research, vol. 85, no. 14, pp. 3118-3126, 2007.

[95] H. Jiang, Z.-M. Qian, and J.-X. Xie, "Increased DMT1 expression and iron content in MPTP-treated C57BL/6 mice," Acta Physiologica Sinica, vol. 55, no. 5, pp. 571-576, 2003.

[96] J. Salazar, N. Mena, S. Hunot et al., "Divalent metal transporter 1 (DMT1) contributes to neurodegeneration in animal models of Parkinson's disease," Proceedings of the National Academy of Sciences of the United States of America, vol. 105, no. 47, pp. 18578-18583, 2008.

[97] A. Donovan, C. A. Lima, J. L. Pinkus et al., "The iron exporter ferroportin/Slc40al is essential for iron homeostasis," Cell Metabolism, vol. 1, no. 3, pp. 191-200, 2005.

[98] N. E. Hellman and J. D. Gitlin, "Ceruloplasmin metabolism and function," Annual Review of Nutrition, vol. 22, pp. 439-458, 2002.
[99] M.-C. Boll, M. Alcaraz-Zubeldia, S. Montes, and C. Rios, "Free copper, ferroxidase and SOD1 activities, lipid peroxidation and NOx content in the CSF. A different marker profile in four neurodegenerative diseases," Neurochemical Research, vol. 33, no. 9, pp. 1717-1723, 2008.

[100] M.-C. Boll, J. Sotelo, E. Otero, M. Alcaraz-Zubeldia, and C. Rios, "Reduced ferroxidase activity in the cerebrospinal fluid from patients with Parkinson's disease," Neuroscience Letters, vol. 265, no. 3, pp. 155-158, 1999.

[101] S. Olivieri, A. Conti, S. Iannaccone et al., "Ceruloplasmin oxidation, a feature of parkinson's disease CSF, inhibits ferroxidase activity and promotes cellular iron retention," Journal of Neuroscience, vol. 31, no. 50, pp. 18568-18577, 2011.

[102] R. Martínez-Hernández, S. Montes, J. Higuera-Calleja et al., "Plasma ceruloplasmin ferroxidase activity correlates with the nigral sonographic area in Parkinson's disease patients: a pilot study," Neurochemical Research, vol. 36, no. 11, pp. 2111-2115, 2011.

[103] K. J. Bharucha, J. K. Friedman, A. S. Vincent, and E. D. Ross, "Lower serum ceruloplasmin levels correlate with younger age of onset in Parkinson's disease," Journal of Neurology, vol. 255, no. 12, pp. 1957-1962, 2008.

[104] G. Tórsdóttir, J. Kristinsson, S. Sveinbjörnsdóttir, J. Snaedal, and T. Jóhannesson, "Copper, ceruloplasmin, superoxide dismutase and iron parameters in Parkinson's disease," Pharmacology and Toxicology, vol. 85, no. 5, pp. 239-243, 1999.

[105] L. Jin, J. Wang, L. Zhao et al., "Decreased serum ceruloplasmin levels characteristically aggravate nigral iron deposition in Parkinson's disease," Brain, vol. 134, no. 1, pp. 50-58, 2011.

[106] L. Jin, J. Wang, H. Jin et al., "Nigral iron deposition occurs across motor phenotypes of Parkinson's disease," European Journal of Neurology, vol. 19, no. 7, pp. 969-976, 2012.

[107] G. Tórsdóttir, S. Sveinbjörnsdóttir, J. Kristinsson, J. Snaedal, and T. Jóhannesson, "Ceruloplasmin and superoxide dismutase (SOD1) in Parkinson's disease: a follow-up study," Journal of the Neurological Sciences, vol. 241, no. 1-2, pp. 53-58, 2006.

[108] D. A. Loeffler, P. A. LeWitt, P. L. Juneau et al., "Increased regional brain concentrations of ceruloplasmin in neurodegenerative disorders," Brain Research, vol. 738, no. 2, pp. 265-274, 1996.

[109] P. Lei, S. Ayton, D. I. Finkelstein, P. A. Adlard, C. L. Masters, and A. I. Bush, "Tau protein: relevance to Parkinson's disease," International Journal of Biochemistry and Cell Biology, vol. 42, no. 11, pp. 1775-1778, 2010.

[110] P. Lei, S. Ayton, D. I. Finkelstein et al., “Tau deficiency induces parkinsonism with dementia by impairing APP-mediated iron export," Nature Medicine, vol. 18, no. 2, pp. 291-295, 2012.

[111] J. A. Duce, A. Tsatsanis, M. A. Cater et al., "Iron-export ferroxidase activity of $\beta$-amyloid precursor protein is inhibited by zinc in Alzheimer's disease," Cell, vol. 142, no. 6, pp. 857-867, 2010.

[112] D. S. Kalinowski and D. R. Richardson, "The evolution of iron chelators for the treatment of iron overload disease and cancer," Pharmacological Reviews, vol. 57, no. 4, pp. 547-583, 2005.

[113] D. Devos, C. Moreau, J. C. Devedjian et al., “Targeting chelatable iron as a therapeutic modality in Parkinson's disease," Antioxidants and Redox Signaling.

[114] M. D. Habgood, Z. D. Liu, L. S. Dehkordi, H. H. Khodr, J. Abbott, and R. C. Hider, "Investigation into the correlation between the structure of hydroxypyridinones and blood-brain barrier permeability," Biochemical Pharmacology, vol. 57, no. 11, pp. 1305-1310, 1999. 
[115] S. Gal, H. Zheng, M. Fridkin, and M. B. H. Youdim, "Restoration of nigrostriatal dopamine neurons in post-MPTP treatment by the novel multifunctional brain-permeable iron chelator-monoamine oxidase inhibitor drug, M30," Neurotoxicity Research, vol. 17, no. 1, pp. 15-27, 2010.

[116] D. T. Dexter, F. R. Wells, F. Agid et al., "Increased nigral iron content in postmortem Parkinsonian brain," The Lancet, vol. 2, no. 8569, pp. 1219-1220, 1987.

[117] E. Sofic, P. Riederer, H. Heinsen et al., "Increased iron (III) and total iron content in post mortem substantia nigra of parkinsonian brain," Journal of Neural Transmission, vol. 74, no. 3, pp. 199-205, 1988.

[118] P. Riederer, E. Sofic, W.-D. Rausch et al., "Transition metals, ferritin, glutathione, and ascorbic acid in parkinsonian brains," Journal of Neurochemistry, vol. 52, no. 2, pp. 515-520, 1989.

[119] R. J. Uitti, A. H. Rajput, B. Rozdilsky, M. Bickis, T. Wollin, and W. K. Yuen, "Regional metal concentrations in Parkinson's disease, other chronic neurological diseases, and control brains," Canadian Journal of Neurological Sciences, vol. 16, no. 3, pp. 310314, 1989.

[120] D. T. Dexter, F. R. Wells, A. J. Lees et al., "Increased nigral iron content and alterations in other metal ions occurring in brain in Parkinson's disease," Journal of Neurochemistry, vol. 52, no. 6, pp. 1830-1836, 1989.

[121] D. T. Dexter, A. Carayon, F. Javoy-Agid et al., "Alterations in the levels of iron, ferritin and other trace metals in Parkinson's disease and other neurodegenerative diseases affecting the basal ganglia," Brain, vol. 114, no. 4, pp. 1953-1975, 1991.

[122] E. C. Hirsch, J.-P. Brandel, P. Galle, F. Javoy-Agid, and Y. Agid, "Iron and aluminum increase in the substantia nigra of patients with Parkinson's disease: an X-ray microanalysis," Journal of Neurochemistry, vol. 56, no. 2, pp. 446-451, 1991.

[123] E. Sofic, W. Paulus, K. Jellinger, P. Riederer, and M. B. H. Youdim, "Selective increase of iron in substantia nigra zona compacta of Parkinsonian brains," Journal of Neurochemistry, vol. 56, no. 3, pp. 978-982, 1991.

[124] P. F. Good, C. W. Olanow, and D. P. Perl, "Neuromelanincontaining neurons of the substantia nigra accumulate iron and aluminum in Parkinson's disease: a LAMMA study," Brain Research, vol. 593, no. 2, pp. 343-346, 1992.

[125] V. M. Mann, J. M. Cooper, S. E. Daniel et al., "Complex I, iron, and ferritin in Parkinson's disease substantia nigra," Annals of Neurology, vol. 36, no. 6, pp. 876-881, 1994.

[126] D. A. Loeffler, J. R. Connor, P. L. Juneau et al., "Transferrin and iron in normal, Alzheimer's disease, and Parkinson's disease brain regions," Journal of Neurochemistry, vol. 65, no. 2, pp. 710716, 1995.

[127] P. D. Griffiths, B. R. Dobson, G. R. Jones, and D. T. Clarke, "Iron in the basal ganglia in Parkinson's disease. An in vitro study using extended X-ray absorption fine structure and cryoelectron microscopy," Brain, vol. 122, no. 4, pp. 667-673, 1999.

[128] A. E. Oakley, J. F. Collingwood, J. Dobson et al., "Individual dopaminergic neurons show raised iron levels in Parkinson disease," Neurology, vol. 68, no. 21, pp. 1820-1825, 2007.

[129] B. F. G. Popescu, M. J. George, U. Bergmann et al., "Mapping metals in Parkinson's and normal brain using rapid-scanning $\mathrm{x}$-ray fluorescence," Physics in Medicine and Biology, vol. 54, no. 3, pp. 651-663, 2009.

[130] K. J. Schweitzer, T. Brüssel, P. Leitner et al., "Transcranial ultrasound in different monogenetic subtypes of Parkinson's disease," Journal of Neurology, vol. 254, no. 5, pp. 613-616, 2007.
[131] J. M. Hagenah, I. R. König, B. Becker et al., "Substantia nigra hyperechogenicity correlates with clinical status and number of Parkin mutated alleles," Journal of Neurology, vol. 254, no. 10, pp. 1407-1413, 2007.

[132] J. M. Hagenah, B. Becker, N. Brüggemann et al., “Transcranial sonography findings in a large family with homozygous and heterozygous PINK1 mutations," Journal of Neurology, Neurosurgery and Psychiatry, vol. 79, no. 9, pp. 1071-1074, 2008.

[133] N. Brüggemann, J. Hagenah, K. Stanley et al., "Substantia nigra hyperechogenicity with LRRK2 G2019S mutations," Movement Disorders, vol. 26, no. 5, pp. 885-888, 2011.

[134] J. M. Shulman, P. L. De Jager, and M. B. Feany, "Parkinson's disease: genetics and pathogenesis," Annual Review of Pathology, vol. 6, pp. 193-222, 2011. 

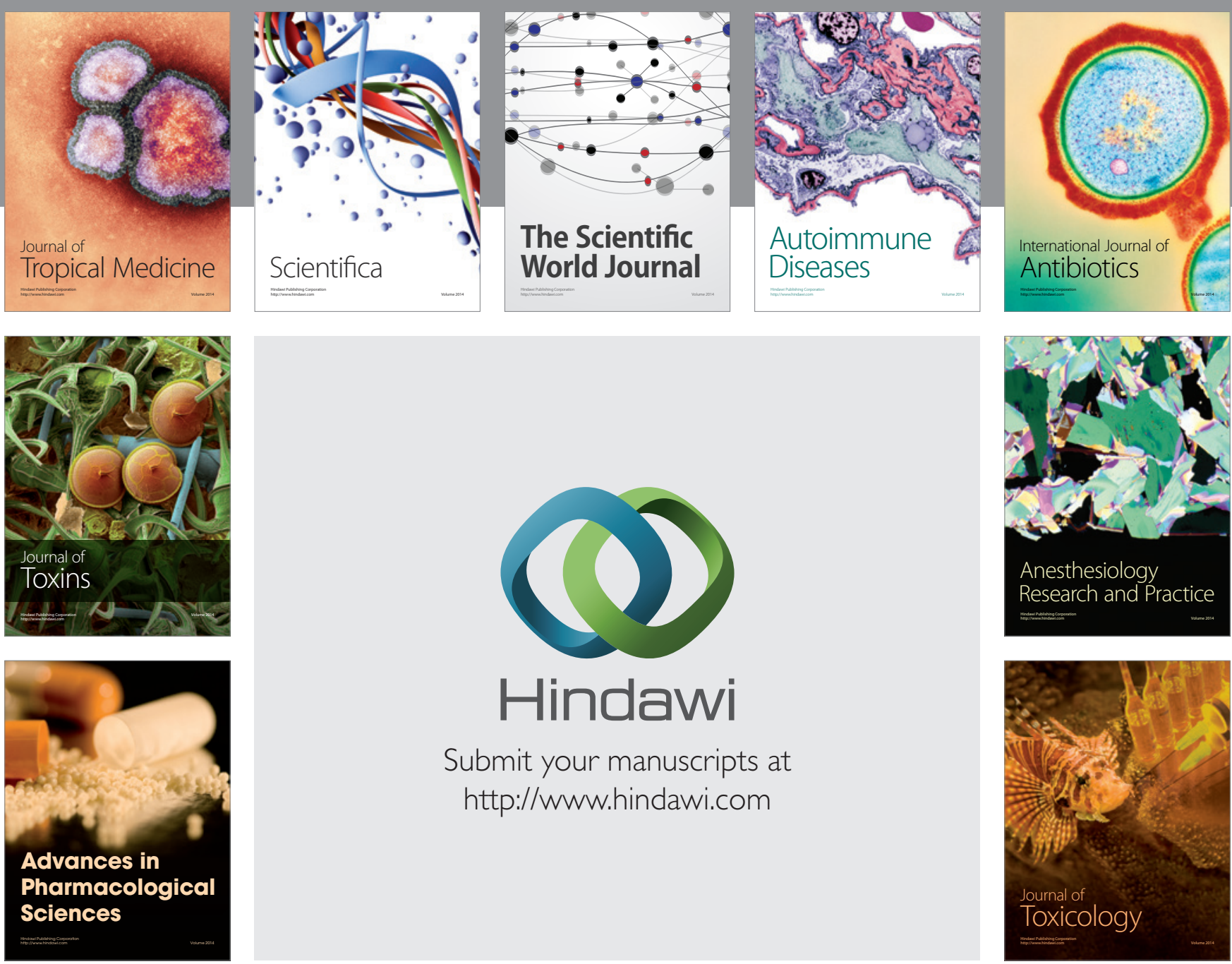

\section{Hindawi}

Submit your manuscripts at

http://www.hindawi.com
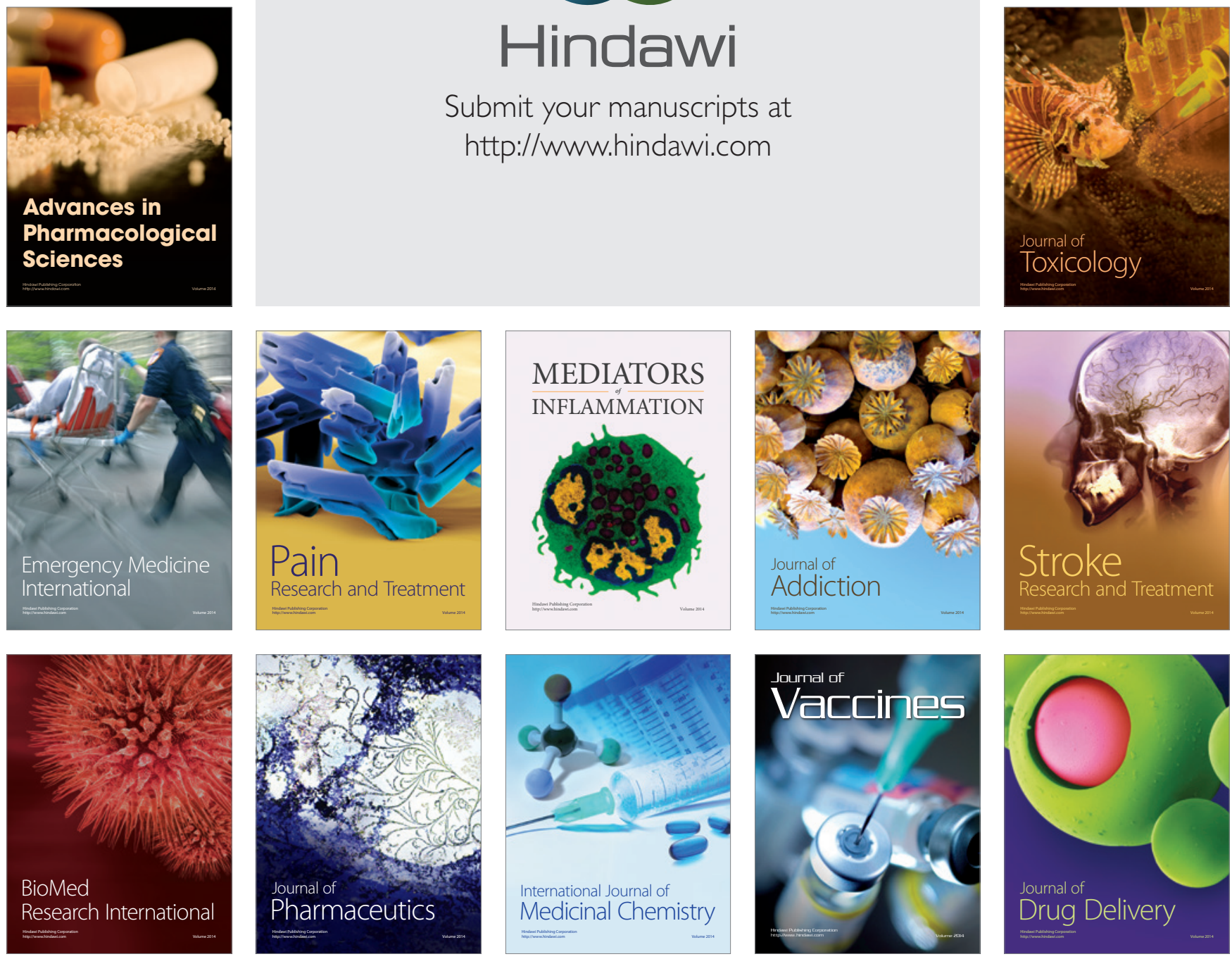